\title{
Gliadin genotypes worldwide for spring wheats (Triticum aestivum L.) 1 . Genetic diversity and grain-quality gliadin alleles during the 20th century
}

\author{
E. Metakovsky ${ }^{\mathrm{a}}$, V.A. Melnik ${ }^{\mathrm{b}}$, L. Pascual ${ }^{\mathrm{a}}$, C.W. Wrigley ${ }^{\mathrm{c}, *, 1}$ \\ ${ }^{a}$ Unit of Genetics, Department of Biotechnology - Plant Biology, Universidad Politecnica de Madrid, Madrid, 28040, Spain \\ ${ }^{\mathrm{b}}$ N.I.Vavilov Institute of General Genetics RAS, Moscow, Russia \\ ${ }^{\mathrm{c}}$ QAAFI, University of Queensland, Brisbane, QLD, 4072, Australia
}

\section{A R T I C L E I N F O}

\section{Keywords:}

Dough quality

Genetic diversity

Genetic erosion

History

\begin{abstract}
A B S T R A C T
High genetic diversity $(H=0.85 \pm 0.03)$ of spring common wheats (290 cultivars from nine countries, four continents) was discovered through the identification of alleles at the gliadin-encoding (Gli) loci. There were no indications of the existence of genetic erosion (narrowing of polymorphism with time) either for wheat germplasm studied throughout the 20th century, or in the group of cultivars bred in any country. At the same time, there was a significant change of the frequency of occurrence, in wheat germplasm of Australia, Canada, Mexico, Nordic countries, Spain, and the former USSR, of certain gliadin alleles related (as shown earlier) to end-use wheat quality, mainly to dough strength. The increase in frequency, in genotypes of groups of more recent cultivars, of gliadin alleles positively influencing dough strength (Gli-B1b, Gli-B1d, and Gli-B2c) caused a loss of genetic diversity at the corresponding Gli loci. It is suggested that these alleles may serve as an indirect targets of breeders' selection for dough quality. Mechanisms of the involvement of some allelic variants of the Gli loci in the manipulation of dough quality are discussed.
\end{abstract}

\section{Introduction}

During the 20th century, the common way for wheat improvement was based on crosses between different genotypes. However, the repeated use in breeding of a restricted number of parental genotypes, successful in producing new cultivars, may cause a decrease of the level of genetic diversity of wheat germplasm and thereby restrict the potential of wheat improvement (Porceddu et al., 1988). One of the main factors which may influence negatively on wheat genetic diversity is the selection, common for many countries during the second part of the 20th century, for improved end-use (dough) quality. There is a set of reliable genetic markers which may be used for the evaluation not only of the diversity of wheat germplasm in general, but, at the same time, to reveal its possible temporal changes which might be caused by the selection for quality. These markers are provided by the wheat seed storage protein complex, gliadin.

The gliadins possess a unique assortment of merits: immense polymorphism, well-studied genetics, and complex structure of the gliadincoding loci (Gli) which include different alleles. The synthesis of gliadins is encoded at the six main Gli loci (Gli-A1, Gli-B1, Gli-D1, Gli-A2, Gli-B2, Gli-D2), and a vast multiple allelism has been described for each of these loci. Each allele at each Gli locus encodes several polypeptides ("a block") inherited as a Mendelian co-dominant trait. Recombination frequency between gliadin-coding genes of a Gli locus does not exceed 1\% (reviewed in Metakovsky, 2015).

Alleles at the Gli loci might be identified through the electrophoretic analysis of the set of different gliadin polypeptides produced by a given wheat genotype. It is established that gliadin electrophoregrams do not depend on the growing conditions of the plant (eco-climatic conditions, the level of fertilization and/or watering), nor on grain protein content or on the maturity of the grain. Alleles at the same locus differ in number and in the electrophoretic mobility of the respective gliadin polypeptides composing a block (reviewed in Metakovsky, 2015). A recent catalogue includes more than 180 alleles, in sum, at the six Gli loci, and there was no instance of the identity of gliadin genotypes for two unrelated cultivars among more than 1000 cultivars studied (Metakovsky et al., 2018b). Obviously, in their resolving power, the extensive family of gliadin alleles may successfully compete with other genetic markers, including any DNA markers, for wheat genotype identification and distinction and, therefore, for evaluation of genetic diversity in a group of cultivars.

In addition, an important advantage of gliadins as genetic markers

\footnotetext{
* Corresponding author.

E-mail address: C.Wrigley1@uq.edu.au (C.W. Wrigley).

${ }^{1}$ Home address: 2 Duncan Pl., Epping. NSW. Australia
} 
would be their relation to dough quality. It has been demonstrated that the contribution of the gliadin fraction of gluten is to dough extensibility and loaf volume of bread rather than to dough strength, the latter balancing characteristic being attributed especially to the glutenin fraction, which (unlike the gliadins) have cysteine residues to form intermolecular bonds. Thus, it was shown that a higher proportion of gliadin in flour reduces dough strength (Gupta and MacRitchie, 1994).

An influence of individual gliadin alleles on dough quality has been documented in many publications (reviewed in Metakovsky, 2015) and explained (Payne et al., 1984) through the linkage of the Gli-1 and Glu-3 loci. It is known that synthesis of the wheat-seed storage protein, lowmolecular-weight (LMW) glutenin, is encoded at the Glu-A3, Glu-B3, and Glu-D3 loci, tightly linked to the Gli-A1, Gli-B1, and Gli-D1 loci, respectively (Payne et al., 1984; Singh and Shepherd, 1988). The recombination frequency between Gli-1 and Glu-3 loci does not exceed $3 \%$ in different studies (reviewed in Metakovsky, 2015). Moreover, analysis of some extended DNA sequences shows that there is no clear border between Gli-1 and Glu-3 loci at the DNA level (Gao et al., 2007; Anderson et al., 2012).

Also, it was discovered that, in some variants of the complex Gli loci, there are genes encoding polypeptides similar to LMW glutenin subunits (Kasarda et al., 1987; Lew et al., 1992; Anderson et al., 2001; Masci et al., 2002; reviewed in Metakovsky, 2015).

In general, there is no doubt now that allelic variation at the DNA regions of common wheat chromosomes marked by each of the six Gli loci make significant contributions to end-use wheat quality via the casual effects of Gli-1 and/or Glu-3 alleles. Therefore, the gliadin alleles are likely to be involved in breeders' selection (positive or negative) as indirect targets for modifying grain quality. To provide new insights into relationships between common breeding for dough properties and wheat genetic diversity, it would be valuable to evaluate the possible effects of breeders' selection on the frequency of some gliadin alleles known to relate to end-use wheat quality.

In this work, we studied, using gliadin alleles, the diversity of spring common wheat germplasm worldwide with respect to time scale throughout the 20th century. Also, we intended to find gliadin alleles and Gli loci which might be indirectly involved in breeders' activity and that thereby might influence changes in genetic diversity for wheat in the future.

\section{Materials and methods}

\subsection{Grain materials}

Nearly all grain samples of spring common wheat (T. aestivum L.) were obtained from genetic and/or breeding laboratories from the countries of origin of the cultivars studied. The internet site (wheatpedigree.net) was used to establish the pedigree of a cultivar, its winter/spring habit, year of release, and the country where it was bred. Also, we followed the spelling of names of cultivars used at this site.

In total, Gli alleles in 290 cultivars bred in nine countries situated in four continents were identified.

\subsection{Methods}

The gliadin allele compositions for 275 spring cultivars used in our analysis have been published earlier (Metakovsky et al., 2018b). Gliadin alleles for a further 15 varieties were identified in this work (Table S1, Supplementary materials) using the procedure described earlier (Metakovsky et al., 2018b). The full list of cultivars involved in this work is presented in the List S1 (Supplementary materials).

An allele occurring with the frequency of $>40 \%$ at a given Gli locus in a given group of cultivars was assumed to be the most frequent gliadin allele (MFGA) (Table 1). Frequency of the most frequent allele at each Gli locus in each group of cultivars studied is also shown (Table
S2, Supplementary materials).

The Nei's genetic diversity index $(H)$ at a Gli locus in a group of cultivars was computed as $H=1-\Sigma p^{2}$, where $p$ is the frequency of an allele at this locus. The overall diversity in a group of cultivars was assumed to be an average of $H$ obtained for each of the six Gli loci.

The significance of the difference of occurrence of an allele in two temporal groups of cultivars was analyzed by the $\chi^{2}$ test with one degree of freedom (Rana and Singhal, 2015).

\section{Results}

Genetic diversity of the 290 spring common wheat cultivars studied was as high as $H=0.85 \pm 0.03$. To provide insight into possible changes of genetic diversity of cultivars bred during the 20th century, 280 cultivars with known year of registration were divided into eight temporal groups with similar numbers of cultivars in each: 1901-30 (29 cultivars); 1931-50 (38); 1951-62 (35); 1963-69 (40); 1970-75 (35); 1976-80 (35); 1981-85 (33); and 1986-93 (35).

The level of genetic diversity at a germplasm-studied scale varied during the 20th century between $H=0.80 \pm 0.04$ (1986-93) and $H=0.85 \pm 0.02$ (1963-69) with an insignificant decrease with time not exceeding 0.04 units of $H$ during the whole century (Fig. 1). Therefore, we did not find any reliable indication of decrease of genetic diversity of spring common wheat, at the world germplasm level, during the 20th century. It should be noted, however, that results of analysis of genetic variation in global wheat germplasm performed by joining together cultivars from many countries may not reflect the temporal processes occurring in wheat germplasm of each country. Therefore, genotypes in groups of cultivars bred at different times during the 20th century in each country were studied. To compare genotypes of cultivars released in a time course, all cultivars bred in one country were divided into temporal groups, with similar numbers of cultivars in each group (Table 1).

Judging from our results (Table 1), the wheat germplasm of Australia has undergone two dramatic changes in its set of the MFGA (after 1950 and after 1973): only allele Gli-B1b (Fig. 2) occurred as the MFGA throughout of the 20th century. It was found that three alleles, Gli-A1a (Fig. 2b), Gli-B2c (Fig. 2a-d), and Gli-D2q spread over Australian wheats so that frequencies of these alleles in the last temporal group of cultivars studied (1974-85) were significantly higher than in cultivars bred in the first part of the 20th century. The increase of the frequency of these three alleles was accompanied by an elimination from Australian wheat germplasm of the alleles Gli-A1m, Gli-B2an, and Gli-D2w, respectively (see Table 2), which are present in the ancient cultivars Gluyas Early, Nabawa and Ranee (see Table S1 in Metakovsky et al., 2018b).

In spite of these changes in allelic frequencies, the overall diversity index $H$ and the number of different gliadin alleles in a group were identical, comparing four temporal groups of Australian cultivars (Table 1). Through application of DNA markers, it was also established earlier that the genetic diversity of Australian wheat was relatively high throughout the 20th century (White et al., 2008).

In Spain, a considerable difference of genotypes, judging from sets of MFGA, between two temporal groups of cultivars studied was observed, but there were no changes either in the genetic diversity or in the number of Gli alleles identified (Table 1). However, there was a significant increase, as in Australia, in the group of more recent cultivars, of the frequency of the allele Gli-A1a accompanied by the complete elimination of the allele Gli-A1m (Tables 1 and 2).

A fall of the genetic diversity accompanied by a decrease of the number of Gli alleles was observed in Canadian cultivars released in 1953-85. However, in the group of the most recent cultivars studied (1986-88), both these parameters have fully recovered. A few differences in the MFGA between temporal groups of cultivars studied were observed (Table 1), but there were at least five statistically significant differences between genotypes in the group of eight cultivars bred in 
Table 1

Sets of the most frequent gliadin alleles (MFGA), the value of genetic diversity $H$, and number of different alleles present in groups of common wheat cultivars bred in different countries during the 20th century.

\begin{tabular}{|c|c|c|c|c|c|c|c|c|c|c|}
\hline \multirow[t]{2}{*}{$\mathrm{N}^{\mathrm{a}}$} & \multirow[t]{2}{*}{ Country ${ }^{b}$} & \multirow[t]{2}{*}{ Years } & \multicolumn{6}{|c|}{ The most frequent allele at the Gli loci } & \multirow[t]{2}{*}{$H^{\mathrm{c}}$} & \multirow[t]{2}{*}{ Number of alleles } \\
\hline & & & $-A 1$ & $-B 1$ & $-D 1$ & $-A 2$ & $-B 2$ & $-D 2$ & & \\
\hline 16 & Australia & $1901-49$ & $m$ & $b$ & $a$ & $a$ & an & $w$ & 0.66 & 31 \\
\hline 16 & Australia & $1951-66$ & $-{ }^{d}$ & $b$ & - & $\boldsymbol{c}+\boldsymbol{a}^{\mathrm{e}}$ & - & - & 0.68 & 31 \\
\hline 16 & Australia & $1967-73$ & - & $b$ & - & $c$ & $c$ & - & 0.69 & 30 \\
\hline 15 & Australia & $1974-85$ & $a^{\mathrm{f}}$ & $\boldsymbol{b}$ & $\boldsymbol{b}$ & $\boldsymbol{f}^{\mathrm{f}}$ & $c$ & $q$ & 0.65 & 31 \\
\hline 8 & Canada & $1907-52$ & $m$ & $b$ & $a$ & $m$ & $c$ & $m$ & 0.55 & 19 \\
\hline 8 & Canada & $1953-72$ & $m$ & $d$ & $j$ & $m$ & $c$ & $\boldsymbol{h}$ & 0.34 & 15 \\
\hline 9 & Canada & $1974-85$ & $m$ & $d$ & $j$ & $m$ & $c$ & $\boldsymbol{h}$ & 0.39 & 18 \\
\hline 6 & Canada & $1986-88$ & - & $d$ & $j$ & $f$ & $c$ & - & 0.54 & 19 \\
\hline 10 & Italy & $1913-55$ & $a$ & - & - & - & - & - & 0.73 & 31 \\
\hline 8 & Italy & $1966-87$ & $a$ & - & $k$ & - & - & - & 0.73 & 32 \\
\hline 7 & Mexico & $1962-66$ & $a$ & $\boldsymbol{b}$ & $\boldsymbol{b}$ & - & $c$ & - & 0.57 & 21 \\
\hline 6 & Mexico & $1967-76$ & $o$ & $d$ & - & $f$ & $c$ & $j$ & 0.56 & 20 \\
\hline 7 & NC & $1921-68$ & $m$ & $k$ & $a$ & $m$ & $g$ & $a$ & 0.52 & 18 \\
\hline 8 & NC & $1972-81$ & $o$ & $b$ & $a$ & $u$ & - & - & 0.59 & 22 \\
\hline 19 & former USSR & $1923-45$ & - & $e$ & $a$ & $q$ & - & - & 0.68 & 38 \\
\hline 20 & former USSR & $1946-59$ & - & $e$ & $a$ & $q$ & - & - & 0.67 & 40 \\
\hline 19 & former USSR & $1961-75$ & - & $e$ & $a$ & $q$ & - & $e$ & 0.67 & 42 \\
\hline 19 & former USSR & $1976-80$ & $f$ & $e$ & $a$ & $q$ & - & e & 0.65 & 45 \\
\hline 16 & former USSR & $1981-86$ & - & $e$ & $a$ & - & - & - & 0.67 & 45 \\
\hline 17 & former USSR & 1987-93 & - & $\boldsymbol{b}+\boldsymbol{e}^{\mathrm{e}}$ & $a$ & - & - & - & 0.71 & 40 \\
\hline 6 & Spain & $1921-66$ & $m$ & - & $i$ & - & - & $a$ & 0.70 & 26 \\
\hline 9 & Spain & $1975-92$ & $a$ & - & $\boldsymbol{b}$ & - & $c$ & - & 0.73 & 28 \\
\hline
\end{tabular}

a Number of cultivars in the group.

b Canada without Quebec; NC: Finland (6 cultivars) + Norway (5) + Sweden (5).

c For Nordic countries, $H$ was calculated using data for five Gli loci (without Gli-B2).

d No single allele reached $40 \%$ for a given locus in a given group.

e Two different alleles at the same Gli locus occurred each with a frequency exceeding $40 \%$.

${ }^{\mathrm{f}}$ Frequency of this allele at this locus in this group $=40 \%$.

the first part of the 20th century and nine cultivars released in 1985-88. It was found that the alleles Gli-B1d (Fig. 2c) and Gli-A2f increased their frequencies while Gli-D1a decreased, and the allele Gli-B2w was substituted by Gli-B2c (Table 2). In addition, there was a substitution, identical to that observed in Australia and Spain, of the allele Gli-A1m for Gli-A1a: the decrease of the frequency of the Gli-A1m and the increase of the Gli-A1a were both close to being statistically significant (each, $\mathrm{p}<0.1$ ).

Temporal changes of genotypes of Canadian Hard Red Spring cultivars were documented earlier using different sets of microsatellites as genetic markers although genetic diversity among culivars released from different breeding periods, breeding programs, and ancestral families did not change significantly during the 20th century (Fu et al., 2006). At the same time, a decrease in the level of genetic diversity tested through the loss of some identified and unique alleles was observed (Fu and Somers, 2011).

There were some differences of genotypes between two temporal groups of Mexican cultivars studied without change neither in the genetic diversity nor in the number of Gli alleles identified in each of these two groups (Table 1). The only significant difference of genotypes between the two temporal groups was an increase of the frequency of the allele Gli-B1d (as it was in Canada) in the more recent group (Table 2).

No significant differences were discovered between six temporal groups of the former USSR cultivars either in their sets of the MFGA, or in the level of genetic diversity $H$, or in the number of different alleles present in one group (Table 1). The only significant substitution was an increase, with time, of the frequency of the allele Gli-B1b (Fig. 2a) accompanied by the loss of the Gli-B1m. The local allele Gli-D2s disappeared nearly completely from cultivars bred in 1987-93 (Table 2).

The changes in genotypes of cultivars bred in Italy and Nordic countries (NC) were accompanied by a slight increase in genetic diversity and in the number of alleles found in NC cultivars, and was not reflected in this parameter for Italian ones (Table 1). There were no statistically significant temporal changes of the frequency of any allele in these two germplasms studied, although the frequency of the allele Gli-B1b increased and of the Gli-A1m and Gli-B1k decreased with time in NC (each, $\mathrm{p}<0.1$ ).

Therefore, it was discovered that the genetic diversity $H$ at the

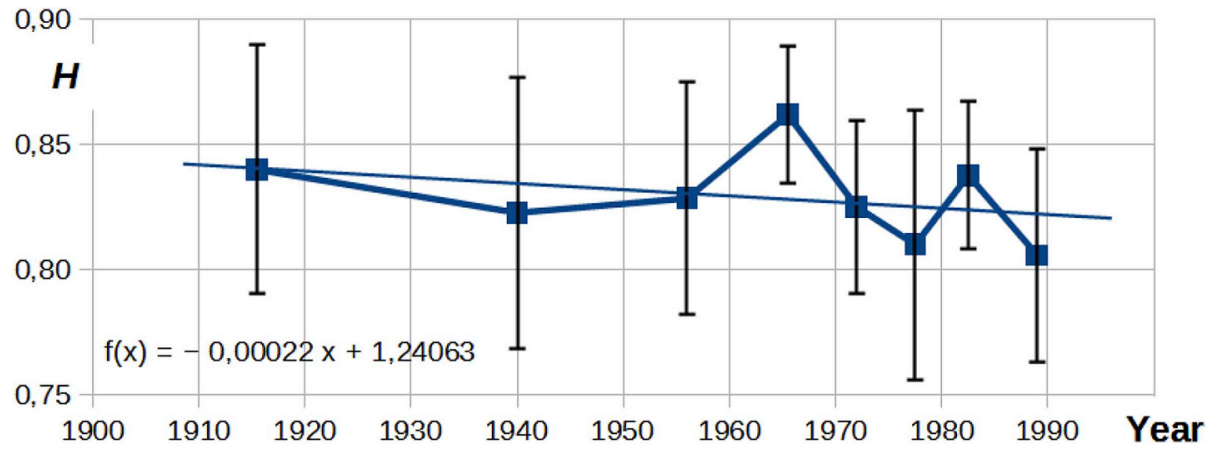

Fig. 1. Levels of genetic diversity $(H)$ and their standard deviations in time-based groups of spring common wheat germplasm during the 20th century. 


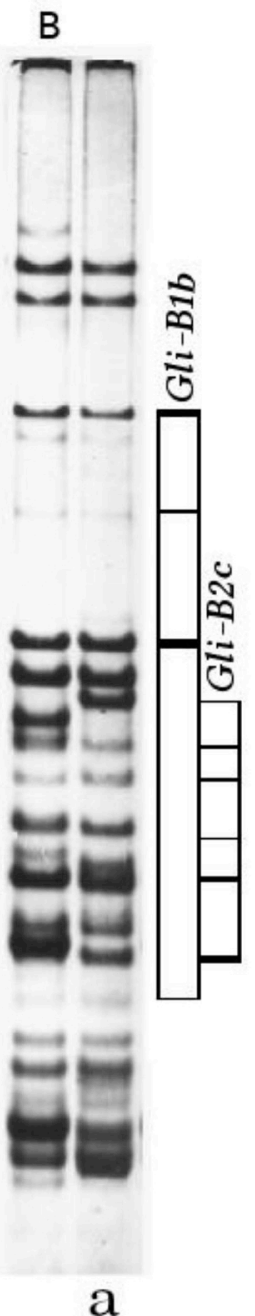

B

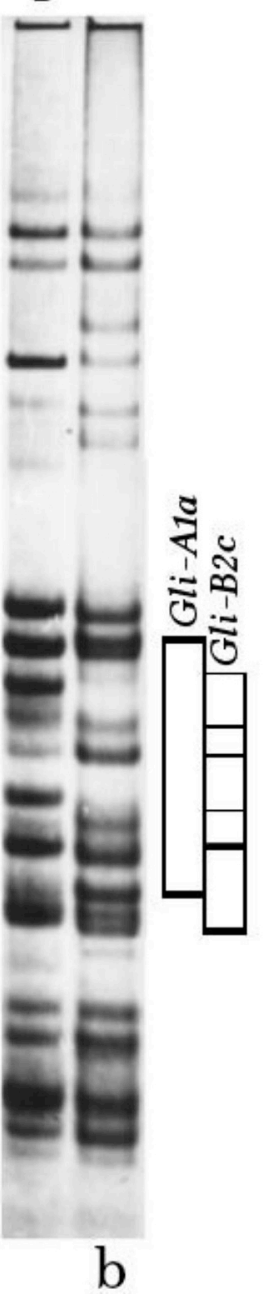

B

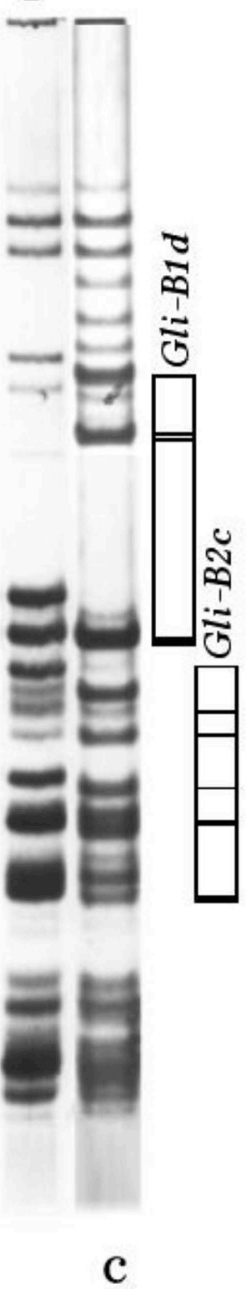

B

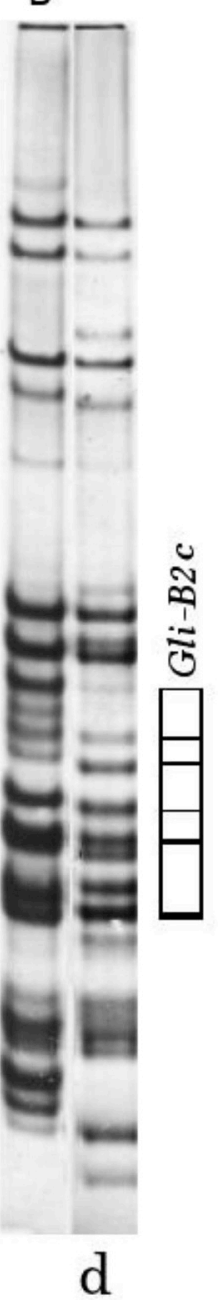

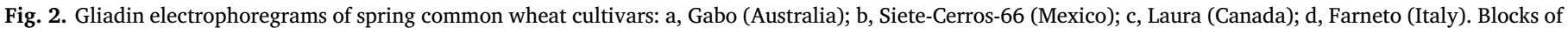

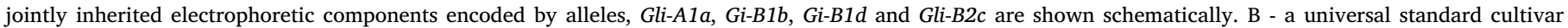
Bezostaya-1.

corresponding individual Gli locus decreased only when the frequency of alleles Gli-B2c (Australia, Canada), or Gli-B1b (the former USSR and, probably, NC), or Gli-B1d (Canada, Mexico) increased with time. Statistically significant temporal increases in the frequency of other gliadin alleles (Gli-A1a, Gli-D1a, Gli-A2f, Gli-D1q) did not reduce the genetic diversity at the corresponding Gli locus (Table 2).

\section{Discussion}

There was no considerable loss of polymorphism of common wheat during the 20th century, as shown using different types of genetic markers (reviewed in Van de Wouw et al., 2010). Our results obtained by using highly-polymorphic gliadin markers for the description of genotypes of spring T. aestivum cultivars bred during the 20th century fully confirmed this conclusion: we did not find indications of narrowing genetic polymorphism with time throughout the 20th century in spring $T$. aestivum neither at a country level, nor at the world-wide germplasm level: there was neither a permanent temporal decrease of the index $H$ nor of the number of registered gliadin alleles.

Analysis of polymorphism of the storage protein gliadin which influences dough quality (Gupta and MacRitchie, 1994) opens a possibility to reveal effects of breeders' selection for higher end-use wheat quality on individual gliadin alleles and Gli loci. In this work, a significant variation of the frequency of certain gliadin alleles, in wheat germplasm of each (except Italy) country studied, was discovered.

Earlier, a few of the many gliadin alleles studied were shown to relate to improved dough quality. For example, only three (Gli-B1b, Gli$A 2 b$ and Gli-B2c), out of 28 gliadin alleles studied, related statistically to dough strength (W) in Italian cultivars (Metakovsky et al., 1997a).

The changes discovered in genotypes of Australian wheat (Table 1) might be caused by the transition from using local cultivars to Mexican (CIMMYT's) wheats (O'Brien et al., 2001). Indeed, the alleles Gli-A1a and Gli-B2c, which increased their frequencies with time in Australian cultivars, are characteristic of Mexican wheats (Table 1). However, the allele Gli-D2q (its frequency also increased with time in Australian germplasm) was not found in Mexican wheats studied. Therefore, changes occurred in Australian germplasm in the 20th century could not be explained only through the appearance of Mexican cultivars in Australian breeding programs.

The presence of the allele Gli-B2c in genotypes from Italy (Metakovsky et al., 1997a) and France (Metakovsky et al., 1997b) (in both cases, mainly winter wheats were studied) correlated statistically with higher dough strength. It is shown now that the frequency of this allele significantly increased with time in Australian and Canadian wheat germplasm. In both these countries, an increase of the occurrence of the allele Gli-B2c was accompanied by a selective loss of genetic diversity at the Gli-B2 locus (Table 2). The allele Gli-B2c is present in each Canadian (without Quebec) cultivar bred in 1985-88 and also 
Table 2

Temporal changes of the genetic frequency of individual alleles and genetic diversity at individual Gli loci.

\begin{tabular}{|c|c|c|c|c|c|c|}
\hline $\mathrm{N}^{\mathrm{a}}$ & Country & Allele $^{\mathrm{b}}$ & Years $^{c}$ & Frequency (\%) ${ }^{\mathrm{d}}$ & $\mathrm{P}^{\mathrm{e}}$ & $\mathrm{H}^{\mathrm{f}}$ \\
\hline 16 & \multirow[t]{20}{*}{ Australia } & \multirow[t]{2}{*}{$\downarrow$ Gli-A1m ${ }^{7}$} & $1901-49$ & 43.8 & \multirow[t]{2}{*}{$* *$} & 0.703 \\
\hline & & & 1974-85 & 6.7 & & 0.702 \\
\hline 16 & & \multirow[t]{2}{*}{$\uparrow G l i-A 1 a$} & $1901-49$ & 0.0 & \multirow[t]{2}{*}{$* * *$} & 0.703 \\
\hline & & & $1974-85$ & 40.0 & & 0.702 \\
\hline 16 & & \multirow[t]{2}{*}{$\downarrow G l i-D 1 a$} & $1901-49$ & 40.6 & \multirow[t]{2}{*}{$*$} & 0.736 \\
\hline & & & 1974-85 & 7.1 & & 0.663 \\
\hline 16 & & \multirow[t]{2}{*}{$\uparrow G l i-D 1 b$} & $1901-49$ & 6.3 & \multirow[t]{2}{*}{$* *$} & 0.736 \\
\hline & & & 1974-85 & 42.9 & & 0.663 \\
\hline 16 & & \multirow[t]{2}{*}{$\uparrow G l i-D 1 f$} & $1901-49$ & 6.3 & \multirow[t]{2}{*}{ * } & 0.736 \\
\hline & & & $1974-85$ & 35.7 & & 0.663 \\
\hline 16 & & \multirow[t]{2}{*}{$\downarrow$ Gli-D1o } & $1901-49$ & 25.0 & \multirow[t]{2}{*}{ * } & 0.736 \\
\hline & & & 1974-85 & 0.0 & & 0.663 \\
\hline 16 & & \multirow[t]{2}{*}{$\uparrow G l i-B 2 c^{\mathrm{h}}$} & $1901-49$ & 12.5 & \multirow[t]{2}{*}{$* * *$} & 0.602 \\
\hline & & & $1974-85$ & 66.7 & & 0.524 \\
\hline 16 & & \multirow[t]{2}{*}{$\downarrow$ Gli-B2an } & $1901-49$ & 56.3 & \multirow[t]{2}{*}{$* * *$} & 0.602 \\
\hline & & & 1974-85 & 0.0 & & 0.524 \\
\hline 16 & & \multirow[t]{2}{*}{$\uparrow G l i-D 2 q$} & $1901-49$ & 10.0 & \multirow[t]{2}{*}{ * } & 0.655 \\
\hline & & & 1974-85 & 43.8 & & 0.694 \\
\hline 16 & & \multirow[t]{2}{*}{$\downarrow$ Gli-D2w } & $1901-49$ & 50.0 & \multirow[t]{2}{*}{$*$} & 0.655 \\
\hline & & & 1974-85 & 13.3 & & 0.694 \\
\hline 8 & \multirow[t]{10}{*}{ Canada } & $\uparrow G l i-B 1 d^{\mathrm{h}}$ & $1907-52$ & 12.5 & * & 0.656 \\
\hline & & & $1985-88$ & 66.7 & & 0.519 \\
\hline 8 & & $\downarrow G l i-D 1 a$ & $1907-52$ & 68.8 & $* * *$ & 0.430 \\
\hline & & & $1985-88$ & 0.0 & & 0.537 \\
\hline 8 & & $\uparrow G l i-A 2 f$ & $1907-52$ & 0.0 & $* *$ & 0.680 \\
\hline & & & $1985-88$ & 50.0 & & 0.654 \\
\hline 8 & & $\uparrow G l i-B 2 c^{\mathrm{h}}$ & $1907-52$ & 62.5 & * & 0.469 \\
\hline & & & $1985-88$ & 100.0 & & 0.000 \\
\hline 8 & & $\downarrow G l i-B 2 w$ & 1907-52 & 37.5 & * & 0.469 \\
\hline & & & $1985-88$ & 0.0 & & 0.000 \\
\hline 7 & Mexico & $\uparrow G l i-B 1 d^{\mathrm{h}}$ & $1962-66$ & 0.0 & $* * *$ & 0.653 \\
\hline & & & 1967-77 & 66.7 & & 0.514 \\
\hline 6 & Spain & $\uparrow G l i-A 1 a$ & $1921-66$ & 0.0 & * & 0.500 \\
\hline & & & 1975-92 & 55.6 & & 0.617 \\
\hline 6 & & $\downarrow$ Gli-A1m ${ }^{\mathrm{g}}$ & $1921-66$ & 66.7 & $* * *$ & 0.500 \\
\hline & & & 1975-92 & 0.0 & & 0.617 \\
\hline 6 & & $\downarrow G l i-D 2 a$ & $1921-66$ & 50.0 & $* *$ & 0.667 \\
\hline & & & 1975-92 & 0.0 & & 0.790 \\
\hline 19 & former USSR & $\uparrow G l i-B 1 b^{\mathrm{h}}$ & $1923-45$ & 6.8 & $* * *$ & 0.732 \\
\hline & & & 1987-93 & 50.0 & & 0.528 \\
\hline 19 & & $\downarrow$ Gli-B1m ${ }^{g}$ & $1923-45$ & 21.1 & * & \\
\hline & & & 1987-93 & 0.0 & & \\
\hline 19 & & $\uparrow G l i-B 2 b$ & $1923-45$ & 0.0 & * & 0.758 \\
\hline & & & 1987-93 & 20.6 & & 0.848 \\
\hline 19 & & $\downarrow G l i-D 2 s$ & $1923-45$ & 28.9 & $*$ & 0.666 \\
\hline & & & 1987-93 & 2.9 & & 0.763 \\
\hline
\end{tabular}

a Number of cultivars studied in a given group for a given locus.

b Alleles whose frequency significantly changed with time: $\downarrow$, decrease; $\uparrow$, increase.

c Years of registration of cultivars composed a given group.

d Frequency of the allele under study in a given group.

e Statistical significance of the alteration of frequency of a given allele in a given group of cultivars (*p $<0.05 ; * * \mathrm{p}<0.02 ; * * \mathrm{p}<0.01$ ).

${ }^{\mathrm{f}}$ Genetic diversity at a given locus in the group of cultivars studied.

$\mathrm{g}$ It was shown earlier that the presence of this allele in common wheat genotype influences negatively on dough quality (dough strength).

$\mathrm{h}$ It was shown earlier that the presence of this allele in common wheat genotype influences positively on dough quality (dough strength).

in each of eight Portugal cultivars studied (see Table S1 in Metakovsky et al., 2018b). All these facts together may indicate indirect breeders' selection, in different countries, in favour of one particular allele (related to end-use wheat quality) at a particular locus.

The fastest polypeptide of the block controlled by the Gli-B2c and located in the $\beta$-zone of an electrophoregram of gliadin (Fig. 2) is a characteristic of this block: it did not occur in other blocks controlled by other known alleles at the Gli-B2 locus. Obviously, it is a mutant form of a polypeptide common to most of the other blocks. The polypeptide encoded by the Gli-B2c has higher electrophoretic mobility and it is shorter than similar ones presented in other blocks (Metakovsky et al., 2018a) probably due to mutational reduction of polyglutamine stretches. Mutational changes in the length of the polyglutamine stretches are usual for the $\alpha$-type gliadin polypeptides (Anderson and Green, 1997; Noma et al., 2016). The allele Gli-B2c has a proven positive influence on dough strength, while it is generally assumed that mutant glutenin-like gliadin polypeptides, encoded at the Gli-2 loci, must have a negative effect on dough quality (Lew et al., 1992; Anderson et al., 2001; Masci et al., 2002).

It was shown earlier, that the allelic variant of the Gli-B1 locus, present in the cultivar Nuri-70, was better in one of the quality parameters studied, namely, dough breakdown value (Lagudah et al., 1988). Our analysis of the data presented in the works of Lagudah et al. (1988) and Masci et al. (2000) led us to the conclusions that, first, the cultivar Nuri-70 possessed, without doubt, the allele Gli-B1d, and second, that exclusively cultivars with this particular allele produced a specific polypeptide of the LMW glutenin type with a molecular mass of $42 \mathrm{kD}$ which might relate to better dough quality (discussed in Metakovsky, 2015). In this work, it was found that the frequency of the allele Gli-B1d significantly increased with time causing a decrease of genetic diversity at the Gli-B2 locus in Canadian and Mexican germplasms. Therefore, it is probable that the allele Gli-B1d may be also (as the Gli-B2c) a target of non-direct breeders' selection because it relates, due to linkage with a glutenin-coding gene, positively to dough quality.

Allele Gli-B1b was recognized earlier as one of the best alleles at the Gli-B1 locus with a positive effect on dough quality, namely, on sedimentation value (several publications of Ukrainian scientists [comparing lines obtained from crosses of different wheat genotypes] mainly of Poperelya and Sozinov (1974-80), reviewed in Metakovsky (2015)). In our work, we revealed that this allele occurred as the most frequent at the Gli-B1 locus throughout the 20th century in Australia (Table 1), its frequency increased significantly with time in the former USSR (Table 2) and, probably, in NC wheat germplasms. It was shown that this allele was nearly always accompanied by the allele Glu-B3b (Gupta et al., 1994) which was one of the strongest alleles at the Glu-3 loci in its positive influence on end-use wheat quality (Gupta et al., 1991). Quite possibly, the positive effects of the Gli-B1b allele were due to its neighbour allele Glu-B3b.

In the former USSR germplasm, an increase of the frequency of the Gli-B1b with time reduced strongly (Table 2) the genetic diversity at the Gli-B1 locus. However, the allele Gli-B1e, characteristic of Russian wheat spring germplasm, maintained its frequency with time, probably because this allele encoded so-called $\omega$-gliadin $\mathrm{d} 4$, which also related positively to dough quality (Branlard et al., 2003).

It was also shown in Ukrainian publications of Poperelya, Sozinov et al. (1974-80) (reviewed in Metakovsky, 2015) that the allele Gli-A1m had a statistically significant negative influence, in the background of winter wheat, on flour quality (tested as sedimentation value). It was shown later that this allele was always accompanied by the Glu-A3e (Jackson et al., 1996) which is one of the worst alleles at the Glu-A3 in relation to dough quality (Gupta et al., 1991). In our work, it was shown that this allele disappeared from the groups of more recent Australian, Spanish, and, probably, Canadian and NC cultivars. Many high-quality Canadian cultivars possess the allele Gli-A1m (Table 1), but its frequency in Canadian germplasm dropped from 75.0\% in 1907-52 to $33.3 \%$ in $1985-88$.

\section{Conclusion}

Alleles at the Gli loci were used as genetic markers of T. aestivum genotypes. No indications of any narrowing of genetic polymorphism throughout the 20th century were found neither at the spring worldwide wheat germplasm level, nor at the country level. At the same time, the frequency of occurrence of some Gli alleles, including those known to relate to dough strength (in particular, Gli-B1b, Gli-B1d and Gli-B2c), significantly increased with time in groups of cultivars bred in the 
different countries studied. It was assumed that alleles related (as shown earlier) to end-use wheat quality, were indirect targets of breeders' selection for this wheat character. Changes in the frequency of occurrence of these alleles in wheat germplasm reduced genetic diversity at the corresponding Gli loci, but did not influence overall wheat genetic diversity.

\section{Conflicts of interest}

The authors declare that they have no conflict of interest.

\section{Appendix A. Supplementary data}

Supplementary data to this article can be found online at https:// doi.org/10.1016/j.jcs.2019.03.008.

\section{References}

Anderson, O.D., Greene, F.C., 1997. The $\alpha$-gliadin gene family. 2. DNA and protein sequence variation, subfamily structure, and origins of pseudogenes. Theor. Appl. Genet. 95, 59-65.

Anderson, O.D., Hsia, C.C., Adelsteins, A.E., Lew, E.J.-L., Kasarda, D.D., 2001. Identification of several new classes of low-molecular-weight wheat gliadin-related proteins and genes. Theor. Appl. Genet. 103, 307-315.

Anderson, O.D., Dong, L., Huo, N., Gu, Y.Q., 2012. A new class of wheat gliadin genes and proteins. PLoS One 7 (12), e52139. https://doi.org/10.1371/journal.pone.0052139.

Branlard, G., Dardevet, M., Amiour, N., Igrejas, G., 2003. Allelic diversity of HMW and LMW glutenin subunits and omega-gliadins in French bread wheat (Triticum aestivum L.). Genet. Resour. Crop Evol. 50, 669-679.

Fu, Y.B., Somers, D.J., 2011. Allelic changes in bread wheat cultivars were associated with long-term wheat trait improvements. Euphytica 179, 209-225.

Fu, Y.B., Peterson, G.W., Yu, J.K., Gao, L., Jia, J., Richards, K.W., 2006. Impact of plant breeding on genetic diversity of the Canadian hard red spring wheat germplasm as revealed by EST-derived SSR markers. Theor. Appl. Genet. 112, 1239-1247.

Gao, S., Gu, Y.Q., Wu, J., Coleman-Derr, D., Huo, N., Crossman, C., Jia, J., Zuo, Q., Ren, Z., Anderson, O.D., Kong, X., 2007. Rapid evolution and complex structural organization in genomic regions harboring multiple prolamin genes in the polyploid wheat genome. Plant Mol. Biol. 65, 189-203.

Gupta, R.B., MacRitchie, F., 1994. Allelic variation at glutenin subunit and gliadin loci, Glu-1, Glu-3 and Gli-1 of common wheats. II.Biochemical basis of the allelic effects on dough properties. J. Cereal Sci. 19, 19-29.

Gupta, R.B., Bekes, F., Wrigley, C.W., 1991. Prediction of physical dough properties from glutenin subunit composition in bread wheats: correlation studies. Cereal Chem. 68, 328-333.

Gupta, R.B., Metakovsky, E.V., Wrigley, C.W., 1994. The relationship between LMWglutenin-subunit and gliadin alleles in Australian wheat cultivars. In: Gluten Proteins, Proc. 5th Internat. Workshop on Gluten Proteins (Detmold, Germany, 1993). Assoc. Cereal Research Publ., pp. 589-597.

Jackson, E.A., Morel, M.H., Sontag-Strohm, T., Branlard, G., Metakovsky, E.V., Redaelli, R., 1996. Proposal for combining the classification systems of alleles of Gli-1 and Glu3 loci in bread wheat (Triticum aestivum L.). J. Genet. Breed. 50, 321-336.

Kasarda, D.D., Adelsteins, A.E., Laird, N.F., 1987. $\gamma$-Gliadins with $\alpha$-type structure coded on chromosome 6B of the wheat (Triticum aestivum L.) cultivar "Chinese Spring". In: Làsztity, R., Békés, F. (Eds.), Proc. 3rd Internat. Workshop on Gluten Proteins. World Scientific, Singapore, pp. 20-29.

Lagudah, E.S., O'Brien, L.O., Halloran, G.M., 1988. Influence of gliadin composition and high molecular weight subunits of glutenin on dough properties in an F3 population of a bread wheat cross. J. Cereal Sci. 7, 33-42.

Lew, E.J.L., Kuzmicky, D.D., Kasarda, D.D., 1992. Characterization of low molecular weight glutenin subunits by reversed-phase high-performance liquid chromatography, sodium dodecyl sulfate-polyacrylamide gel electrophoresis, and $\mathrm{N}$-terminal amino acid sequencing. Cereal Chem. 69, 508-515.

Masci, S., D'Ovidio, R., Lafiandra, D., Kasarda, D.D., 2000. A 1B-coded low-molecular weight glutenin subunit associated with quality in durum wheats shows strong similarity to a subunit present in some bread wheat cultivars. Theor. Appl. Genet. 100, 396-400.

Masci, S., Rovelli, L., Kasarda, D.D., Vensel, W.H., Lafiandra, D., 2002. Characterisation and chromosomal localisation of C-type low-molecular-weight glutenin subunits in the bread wheat cultivar Chinese Spring. Theor. Appl. Genet. 104, 422-428.

Metakovsky, E.V., 2015. Wheat storage proteins: genes, inheritance, variability, mutations, phylogeny, seed production, flour quality. Lambert Acad. Pabl (in Russian, English summary).

Metakovsky, E.V., Annicchiarico, P., Boggini, G., Pogna, N.E., 1997a. Relationships between gliadin alleles and dough strength in Italian common wheats. J. Cereal Sci. 25, 229-236.

Metakovsky, E.V., Felix, I., Branlard, G., 1997b. Association between dough quality (W value) and certain gliadin alleles in French common wheat cultivars. J. Cereal Sci. 26, 371-373.

Metakovsky, E.V., Melnik, V.A., Redaelli, R., Rodriguez-Quijano, M., 2018a. Comparison of alleles at Gli-2 loci of common wheat by means of two-dimensional electrophoresis of gliadin. Cytol. Genet. 52, 87-94.

Metakovsky, E.V., Melnik, V.A., Rodriguez-Quijano, M., Upelniek, V.P., Carrillo, J.M., 2018b. A catalogue of gliadin alleles: polymorphism of 20th-century common wheat germplasm. Crop J. 6, 628-641. https://doi.org/10.1016/j.cj.2018.02.003.

Noma, S., Kawaura, K., Hayakawa, K., Abe, C., Tsuge, N., Ogihara, J., 2016. Comprehensive molecular characterization of the $\alpha / \beta$-gliadin multigen family in hexaploid wheat. Mol. Genet. Genom. 291, 65-77.

O'Brien, L., Morell, M., Wrigley, C., Appels, R., 2001. Genetic pool of Australian wheats. In: Bonjean, A.P., Angus, W.J. (Eds.), The World Wheat Book (Chapter 23). Lavoisier Publishing, Paris, pp. 603-640.

Payne, P.I., Jackson, E.A., Holt, L.M., Law, C.N., 1984. Genetic linkage between endosperm storage protein genes on each of the short arms of chromosomes $1 \mathrm{~A}$ and $1 \mathrm{~B}$ in wheat. Theor. Appl. Genet. 67, 235-243.

Porceddu, E., Ceoloi, C., Lafiandra, D., Tanzarella, O.A., Scarascia Munozza, G.T., 1988. Geneic resources and plant breeding: problems and prospects. In: Miller, T.E., Koebner, R.M.D. (Eds.), Proc. 7th Internat. Wheat Genetics Symposium (v.1). IPSR, Cambridge, UK, pp. 7-22.

Rana, R., Singhal, R., 2015. Chi-squared test and its application in hypothesis testing. J. Pract. Cardiovasc. Sci. 1, 69-71.

Singh, N.K., Shepherd, K.W., 1988. Linkage mapping of genes controlling endosperm storage proteins in wheat. 1 . Genes on the short arms of group 1 chromosomes. Theor. Appl. Genet. 75, 628-641.

Van de Wouw, M., van Hintum, T., Kik, C., van Treuren, R., Visser, B., 2010. Genetic diversity trends in twentieth century crop cultivars: a meta analysis. Theor. Appl. Genet. 120, 1241-1252.

White, J., Law, J.R., MacKay, I., Chalmers, K.J., Smith, J.S.C., Kilian, A., Powell, W., 2008. The genetic diversity of UK, US and Australian cultivars of Triticum aestivum measured by DArT markers and considered by genome. Theor. Appl. Genet. 116, 439-453. 